\title{
Unmet Needs in the Osteoarthritis Chronic Moderate to Severe Pain Management in Spain: A Real Word Data Study
}

\author{
Francisco Castro-Domínguez - Francisco Vargas-Negrín • \\ Concepción Pérez · Héctor Gutiérrez-Prieto · Pablo Rebollo (1)
}

Received: April 19, 2021 / Accepted: May 25, 2021 / Published online: June 9, 2021

(c) The Author(s) 2021

\begin{abstract}
Introduction: Patients with moderate or severe pain due to osteoarthritis (OAP) usually undergo pharmacological treatment with NSAIDs and/or opioids. Many of them do not get adequate pain relief because of intolerances, contraindications and the ineffectiveness of these treatments. The main objective of the
\end{abstract}

Supplementary Information The online version contains supplementary material available at https:// doi.org/10.1007/s40744-021-00327-7.

F. Castro-Domínguez

Rheumatology Unit, Teknon Medical Center, Quirónsalud Group, Barcelona, Spain

F. Castro-Domínguez

Rheumatology Unit, University Hospital "Sagrat

Cor", Quirónsalud Group, Barcelona, Spain

F. Castro-Domínguez

SER Working Group in Osteoarthritis, Spanish

Society of Rheumatology, Madrid, Spain

F. Vargas-Negrín

Healthcare Center Dr. Guigou, Canarian Health

Service, Tenerife, Spain

C. Pérez

Pain Unit, University Hospital "La Princesa",

Madrid, Spain

H. Gutiérrez-Prieto · P. Rebollo ( $₫)$

IQVIA, C/ Juan Esplandiu 11, 6, 28007 Madrid, Spain

e-mail: Pablo.Rebollo@iqvia.com present study was to quantify the group of OAP patients who are inadequately treated for their pain in routine clinical practice in Spain and to describe the prescription flow of these patients. Methods: This was a non-interventional, retrospective cohort study conducted using the IQVIA's electronic medical records database in Spain. Patients with osteoarthritis (OA), aged $\geq 15$ years and receiving any pain treatment during 12 out of 24 months between 1 October 2017 and 30 September 2019 were studied. Assumptions were made to identify patients with contraindication or intolerance to NSAIDs or opioids and those who failed NSAID or opioid therapy.

Results: Out of 136,556 patients with OA, 29,886 had moderate-to-severe pain, which extrapolated to the general population in Spain represents 1,541,286 OAP patients. Mean age (SD) of OAP patients was 75 (12.8) years, and $73.8 \%$ were female; $52.8 \%$ were treated with NSAIDs and/or weak opioids. There were were 16,748 OAP patients (56.08\%) (extrapolated figure 838,620 ) with one or more conditions associated with being inadequately treated (contraindication, intolerance or failed NSAID and/or opioid therapy). In most OAP patients (91\%) pain treatment was initiated by the general practitioner (GP) alone. Considering overall successive therapy lines, after the first prescription, pain drugs were prescribed by a GP in $61 \%$ of the cases, by a specialist in $20 \%$ and by both in $18 \%$. 
Conclusion: More than half of the patients with OA in Spain have unsatisfactory pain control. Pain drugs are mainly prescribed by GPs, and specialists (traumatologists, rheumatologists, physiatrists and pain management specialists) are not very involved in the management of OAP patients.

Keywords: Osteoarthritis; Pain; Treatment; Prescription flow; Real-world data; Spain

\section{Key Summary Points}

Why carry out this study?

The number of patients with moderate or severe pain due to osteoarthritis who do not get pain control because of inadequate treatment is currently unknown in Spain

Patient flow through different medical specialties may not be optimal

The objective of the present study was to quantify the group of OAP patients who are inadequately treated for their pain in routine clinical practice in Spain and to describe the prescription flow of these patients

\section{What was learned from the study?}

More than half of the patients with OA in Spain have unsatisfactory pain control. Traumatologists, rheumatologists, physiatrists and pain management specialists are not very involved in the management of OAP patients with moderate or severe pain

A holistic management of patients with OA, through the implementation of medical programs specifically designed for these patients, with different medical specialties involved, could significantly improve the outcomes currently achieved in Spain with respect to pain control

\section{DIGITAL FEATURES}

This article is published with digital features, including a summary slide, to facilitate understanding of the article. To view digital features for this article go to https://doi.org/10.6084/ m9.figshare.14619033.

\section{INTRODUCTION}

Osteoarthritis (OA) is a disease of the joints in which all the tissues are altered: the cartilage, subchondral bone, synovial membrane, joint capsule, menisci, bursa, ligaments and muscles. $\mathrm{OA}$ is the most prevalent musculoskeletal disease [1]. It is one of the most frequent causes of disability in the elderly, with mechanical pain being the main symptom; therefore, pain relief is the first indication for drug treatment in patients with OA [2]. About $10 \%$ of adults have moderate or severe $\mathrm{OA}$, with incidence increasing with age, with arithmetic growth up to 50-55 years and geometric from that age [2]. The most frequent locations are the cervical and lumbar spine and the distal interphalangeal joints, although the most disabling involvement is the hip and knee [3].

According to the EPISER study [4] (2016), the prevalence of OA (one or more locations) in subjects 40 years or older in Spain was $29.4 \%$, and figures for different locations were as follows: lumbar spine (15.5\%), cervical spine $(10.1 \%)$, hips (5.1\%), knees (13.8\%) and hands (7.7\%). Data from the 2017 National Health and Wellness Survey in Spain [5] showed that the prevalence of OA diagnosed by a physician in the last 12 months was $17.5 \%$ and at any time $22.6 \%$ in the total sample and $29.8 \%$ in subjects aged 40 or over. OA clearly affects the healthrelated quality of life (HRQoL) of patients. The 2001 EPISER study [6], which included subjects $\geq 20$ years, and the ITACA study [1] showed that $\mathrm{OA}$ negatively impacted the physical domain of HRQoL measured by the SF-12 questionnaire. In patients with $\mathrm{OA}$, pain and functional capacity are the most affected dimensions as measured by the WOMAC scale [7], a specific questionnaire for OA. OA has been associated with high economic burden 
(between 0.25 and $0.50 \%$ of a country's gross domestic product) with annual incremental non-healthcare-related costs ranging from $€ 432$ to 11,956 [8]. The absenteeism and presenteeism of people who experience pain have been studied in relation to people without pain by using data from the 2010 National Health and Wellness Survey in Spain [9]; results demonstrated that pain has a significant impact on absenteeism and presenteeism within the employed workforce. The high impact of OA on the patients' life can be understood by knowing that it is responsible for the loss of 1.9 qualityadjusted life years (QALYs) in people between 50 and 84 years of age [10].

According to the Spanish Pain Society (SED), approximately $2 \%$ of patients with chronic pain are found in the pain treatment units, $83 \%$ in primary care and $15 \%$ with specialists [11] but there is no clear or established flow for the patients. Consultations for pain in Spain are very common in both primary care and emergencies. Most (up to 80\%) are resolved in the primary care setting and the rest are referred to the specialist; if they are not resolved there then the patients go to the pain treatment units [11]. Patients with $\mathrm{OA}$ and pain frequently visit the physician as was shown in the 2001 EPISER study [6]. According to the results of this study, $>60 \%$ of the studied subjects with low back pain or knee OA had visited a physician for musculoskeletal problems in the past year, and $>25 \%$ had visited two or more physicians [6]. The interviews carried out by the Pain Proposal Initiative [11], which represents perspectives from different stakeholders from across 15 European countries concerning chronic pain, showed that there are a number of inadequacies in the way chronic pain is currently managed in Spain. Patients have reported long waiting times for referral and persisting pain despite treatment, with consequences for their ability to work and their relationships with partners and family [11]. Inappropriate pain management is associated not only with increased patient suffering but also with great financial costs in terms of loss of work time, reduced levels of productivity and ability to function in society [12].
With respect to the treatment of patients with $\mathrm{OA}$ and pain, several guidelines have been developed in Spain [13-16] and in the world [17-20] to assist physicians and other healthcare professionals in their management of the disease. Clinical guidelines recommend a nonpharmacological core treatment for patients with osteoarthritis which should include weight loss, healthy eating habits, physical activity, self-management of pain, information-education and orthoses [13], along with pharmacological treatment for pain. Which interventions and the order in which interventions are used will vary among patient phenotypes [17]. In reference to this, different experiences exist worldwide about how to adequately organize the core treatment delivery for patients with $\mathrm{OA}$, such as the programs carried out in Australia [21, 22], Sweden [23, 24], the UK [25] and Denmark [26]. To our knowledge, no attempts similar to these experiences have been made in Spain. Treatment decisions should consider the personal beliefs and preferences of the patient as well as the patient's medical status into consideration [17]. Numerous pharmaceutical agents (acetaminophen, metamizole, which is considered an atypical analgesic in Spain although it is a NSAID with strong activity, both non-selective and selective cyclooxygenase-2 [COX-2] inhibitor NSAIDs, topical NSAIDs, tramadol and non-tramadol opioids) can provide clinical benefit in patients with OA, but none has shown all the characteristics of an ideal treatment, and side effects have been reported with both systemic and local administrations $[16,27]$. In this regard it should be noted that many guidelines do not recommend opioids for the treatment of chronic pain associated with OA [17-20]. When choosing among pharmacological therapies, management should begin with treatments with the least systemic exposure or toxicity [17]. A study comparing the use of pharmacotherapies in five European countries (UK, France, Germany, Italy and Spain) [28] showed that half the respondents with OA were currently using prescription medication for pain, varying from 33\% in Germany to the highest rate $(53.2 \%)$ in Spain. OTC medication (including some NSAIDs and acetaminophen) was being used by one quarter of respondents, 
being considerably lower in Spain (14.6\%). The most common classes of prescription medication across the five countries were NSAIDs and weak opioids (low-dose tramadol), with a small number of respondents using COX-2 inhibitors $(6.6 \%)$ and acetaminophen $(4.2 \%)$. The use of prescription medication increased with self-reported severity of pain, with $29.6 \%$ of respondents reporting mild pain using a prescription medication compared with $54.4 \%$ of respondents reporting moderate pain and $77.6 \%$ of those with severe pain [28]. Concerning experience with opioids, according to the analysis of the 2010 National Health and Wellness Survey in Spain [29], it seems that they are mainly prescribed to patients with severe and moderate pain, but also to a significant proportion of patients with mild pain (20\%). The use of opioids in Spain is not as high as in other developed countries, but, according to data collected by the Spanish Agency of Medicinal Products (AEMPS) [30], the use of opioids almost doubled in Spain from 10.03 defined daily doses (DDD) per 1000 inhabitants in 2010 to 19.83 DDD in 2019. The same tendency was observed in a realworld population-based study carried out in Valencia, Spain [31]. In this study it was observed that the annual number of patients receiving at least one opioid prescription more than doubled, from 335,379 in 2010 to 722,838 in 2018.

Non-surgical interventional management is indicated in symptomatic non-surgical knee OA without response to oral and topical analgesic and anti-inflammatory treatment as well as in knee OA in the surgical phase when surgery is inadvisable or contraindicated [32]. Currently, the most widely prescribed options for nonsurgical interventional management are intraarticular steroids, hyaluronic acid (both high and low molecular weight), intra-articular ozone, platelet-rich plasma, botulinum toxin and radiofrequency of geniculate nerves [32].

In summary, OA guideline recommendations are still not being delivered efficiently by healthcare systems worldwide. This could be due to the existence of a knowledge translation gap in the implementation of evidence in the field of OA, directly affecting the efficiency of the OA patient's journey.
Non-oncological chronic pain is complex. As there are no globally accepted recommendations for the pharmacological management of these patients, it seems that treatment of pain associated with OA in Spain needs improvement. Indeed, there is a lack of a national strategic plan to address non-oncological chronic pain, as was highlighted by health professionals [11]. There is a great variability in the management of OA patients between different healthcare levels and between countries [28]. This is more relevant for many patients with moderate or severe pain, mostly treated with NSAIDs and/or opioids, who cannot benefit from some therapeutic steps because of intolerances, contraindications and comorbidities, and also because there is great variability in the effectiveness of treatment.

The main objective of the present study was to quantify the group of OA patients that is inadequately treated for moderate-to-severe pain in routine clinical practice in Spain and classify them according to the underlying reason for inadequate treatment of pain. It was also intended to describe the referral flow of these patients in routine clinical practice in Spain.

\section{METHODS}

This was a non-interventional, retrospective cohort study conducted using IQVIA's Electronic Medical Records (EMR) database in Spain. OA patients aged $\geq 15$ years and receiving any pain treatment during 12 out of 24 months, identified between 1 October 2017 and 30 September 2019, were selected for the study.

IQVIA's EMR database in Spain contains anonymized data collected from 1450 general practitioners (GPs) and 2000 specialists, representing $>600,000$ patients on an annual basis. All physicians participating in the database use EMR software to manage their patients and record information during their daily patient visits, including for writing prescriptions. A panel of physicians using this software volunteered to make anonymized, patient-level information from their practices available for clinical research purposes. Data are transmitted online on a monthly basis. The patient 
identifier is unique through all GP and specialist practices. Since these data are being collected in a non-interventional manner, they reflect routine clinical practice. This database contains individual-level data on demographics (age, gender), comorbidities, healthcare contacts (e.g., date, diagnosis, visits), prescribed drugs (ATC code, strength, daily dose and duration), laboratory tests (date and result) and clinical measurements (e.g., body mass index, blood pressure, pulse) when applicable and enables longitudinal tracking for both patients and prescribers. Subjects included in IQVIA's EMR database have similar distribution by age and gender to the general Spanish population. Data are extrapolated to the national level based on demographic attributes (age and gender). Each patient has a unique extrapolation coefficient according to their age and gender, which is created based on the reference population of each region and total national population of Spain (Source: Instituto Nacional de Estadística).

Variables extracted from the EMR database included sociodemographics (age and gender), OA diagnosis and date, comorbidities, pain treatment during the observation period and speciality of the physician who prescribed treatments. A detailed list of variables and ICD9 and ATC codes used is presented in Table 1. OA duration, age and gender, and treatments received at inclusion date or within the previous month were described for the studied sample. Number of OA patients with moderate-to-severe pain who were inadequately treated were considered to be those meeting one of the following conditions:

1. NSAID contraindication, when having any diagnosis of the following (ICD-9 codes in Table 1): allergy to any NSAID, severe heart failure (NYHA II-IV), severe hepatic failure, severe renal failure, active hemorrhage (including cerebral), history of gastrointestinal hemorrhage and history of gastrointestinal ulceration.

2. Opioid contraindication, when having any diagnosis of the following (ICD-9 codes in Table 1): paralytic ileus, elevated carbon dioxide levels in the blood, delayed gastric emptying, severe respiratory depression (including both, chronic obstructive pulmonary disease and severe asthma), cor pulmonale, moderate-to-severe hepatic impairment and chronic constipation.

3. Failed NSAID or opioid therapy, when patients were prescribed an NSAID or opioid for 1 month and then stopped, and/or contraindicated/intolerant to NSAIDs and failed opioids and/or contraindicated/intolerant to opioids and failed NSAIDs.

4. Intolerant to NSAID or opioid therapy, when patients stopped taking NSAIDs/opioids after the first month and never took NSAIDs/opioids again.

The percentage of patients who met each of the inadequate treatment selection criteria was estimated as well as the percentage of patients who met any of the criteria. Percentages were calculated over the total number of patients. The figures extrapolated to the general Spanish population are shown along with the actual number of patients included in the database.

Percentage of different specialists (general practitioner, traumatologists, rheumatologists, physiatrists, pain management specialists, other specialties) involved in the management of OA patients treated for moderate-to-severe pain was calculated at the following flow points: (1) physician starting treatment; (2) physicians involved at first referral line; (3) physicians involved at any treatment line.

Due to the purely descriptive nature of this study, no sample size calculation was performed. The statistical analysis was based on the selected population in the EMR database, based on previously described fixed criteria. For continuous variables, descriptive statistics are presented as mean and standard deviation (SD) or median and quartiles (25th and 75th percentiles). For categorical variables, statistics are presented as absolute and relative frequencies. When needed, the $95 \%$ CI of the relative frequency was estimated.

The protocol of this study was approved by the Research Ethics Committee of the Hospital Clinic of Barcelona on 26 November 2020 (Reg.HCB/2020/1309). This study was performed in accordance with the Helsinki 
Table 1 Study variables and corresponding ICD-9 and ATC codes

\begin{tabular}{|c|c|}
\hline Variables & ICD-9 code \\
\hline \multirow[t]{5}{*}{$\mathrm{OA}$} & Osteoarthrosis and allied disorders: $715 . x$ \\
\hline & Other and unspecified arthropathies: $716 . \mathrm{x}$ \\
\hline & Internal derangement of knee: $717 . x$ \\
\hline & Other derangement of joint: $718 . x$ \\
\hline & Other and unspecified disorders of joint: $719 . \mathrm{x}$ \\
\hline \multirow[t]{17}{*}{ Comorbidities } & Comorbidities associated to NSAID contraindication ICD-9 codes: \\
\hline & Allergy to any NSAID: $909.5,965.61,995.29$ \\
\hline & $\begin{array}{l}\text { Severe heart failure (NYHA II-IV): 398.91, 402.01, 402.11, 404.01, 404.03, 404.11, 404.13, 428.0, 428.1, } \\
\text { 428.9, 429.4 }\end{array}$ \\
\hline & Severe hepatic failure: $571.3,572.8,573.3$ \\
\hline & Severe renal failure: 583.x, 584.x, 585.x, 586 \\
\hline & $\begin{array}{l}\text { Active hemorrhage (incl. cerebral): } 372.72,376.32,379.23,430,431,432,432.1,432.9,459,519.09,569.3 \text {, } \\
602.1,640.83,640.93,784.8,786.3,786.39,851.41,852.01,853.01,907,997.02,998.11,998.12,998.13\end{array}$ \\
\hline & History of gastrointestinal hemorrhage: $578 . x$ \\
\hline & History of gastrointestinal ulceration: 531.x, 532.x, 534.x, 535.x \\
\hline & Comorbidities associated with opioid contraindication: \\
\hline & Paralytic ileus: 560.1 \\
\hline & Elevated carbon dioxide levels in the blood: $790.91,987.8$ \\
\hline & Delayed gastric emptying: 536.3 \\
\hline & Severe chronic obstructive lung disease: 493.21, 491.21, 493.22, 491.20, 493.20 \\
\hline & Cor pulmonale: $415.0,416.9$ \\
\hline & Severe bronchial asthma: $518.51,518.53,518.81,518.83,518.84$ \\
\hline & $\begin{array}{l}\text { Moderate-to-severe hepatic impairment: 570, 571.40, 571.41, 571.42, 571.49, 571.5, 571.6, 571.8, 571.9, } \\
\text { 572.x, 573.x }\end{array}$ \\
\hline & Chronic constipation: 564.09 \\
\hline Treatment & ATC code \\
\hline \multirow[t]{7}{*}{ Pain treatment } & Acetaminophen: N02BE01 \\
\hline & $\begin{array}{l}\text { NSAIDs: M01AB16, M01AH01, M01AB05, M01AB55, M01AB91, } \\
\text { M01AH05, M01AE09, M01AE01, } \\
\text { M01AB01, M01AX93, M01AE03, M01AG01, M01AC06, M01AX01, M01AE02, } \\
\text { M01AE52, M01AA01, } \\
\text { M01AC01, M01AC02, N02BG9, M01AE14, M01AE17, M01AC05, M01AX02 }\end{array}$ \\
\hline & Weak opioids: N02AJ07, N02AJ08, N02AJ06, N02BE51, N02AX02, N02AJ14, N02AJ13 \\
\hline & $\begin{array}{l}\text { Strong opioids: N02AE01, N02AB03, N02AA03, N07BC02, N02AA01, } \\
\text { N02AA05, N02AA55, N02AB02, N02AX06 }\end{array}$ \\
\hline & Acetylsalicylic acid: N02BA01 \\
\hline & Metamizole: N02BB02 \\
\hline & $\begin{array}{l}\text { Oral corticosteroids: H02AB01, H02AB02, H02AB04, H02AB05, H02AB06, } \\
\text { H02AB07, H02AB08, H02AB09, } \\
\text { H02AB10, H02AB13 }\end{array}$ \\
\hline
\end{tabular}


Declaration of 1964 and its later amendments. Patient consent was not obtained as Spanish legislation excludes existing data that are aggregated for analysis and personal data are stripped of identifying details as specified in Organic Law 3/2018 [33].

\section{RESULTS}

Total number of patients with OA in IQVIA's EMR database was 136,556 during the study period (from 1 October 2017 to 30 September 2019) (Fig. 1). The mean age (SD) of OA patients was 63.68 (17.11) years and $65 \%$ of them were female. Median OA duration (Pc25-Pc75) of these patients was 139 (58-344) days. Relative frequency of treatments received for pain depending on the time under treatment is presented in Fig. 2 for all the patients extracted from the EMR database. Figure 2 shows that use of strong opioids is more frequent in patients with more severe pain. Among them, 29,866 patients $(21.87 \%)$ were treated for pain at least 12 out of 24 months and so were considered OA patients with moderate-to-severe pain (OAP). Figures extrapolated to the Spanish population were $5,937,756$ patients with OA and 1,541,286 patients with OAP.

The median OA duration (Pc25-Pc75) of OAP patients was 587 (463-700) days. The mean age (SD) of OAP patients at inclusion in the study was 75 (12.79) years, while that of the rest of the OA patients was $62.6(17.08)$ years. The majority of OAP patients were female $(73.8 \%)$, similar to the OA patients $(62.9 \%)$. Pain treatments received by OAP patients at inclusion date (or within the previous month) depending on the time under treatment during the last 24 months are presented in Fig. 3. As shown in this figure, most OAP patients were treated with a combination of NSAIDs and weak opioids, NSAIDs alone or weak opioids alone. These three treatments accounted for $52.77 \% \quad(95 \% \quad$ CI $48.04-57.5 \%)$ of the prescribed treatments in the whole sample, decreasing from $67 \%$ in patients treated between 360 and 380 days to $42 \%$ in patients treated during the last 720 days or more.
The numbers of OAP patients with any of the diagnoses associated with NSAID or opioid contraindication in the studied sample are shown in Table 2, along with the figure extrapolated to the Spanish population. Considering that in some cases patients had more than one condition, the total number of OAP patients with NSAID contraindication was 2741 patients $(9.18 \%)$ (extrapolated figure [EF] 129,206) and with opioid contraindication was 1666 patients (5.58\%) (EF 85,710).

Number of OAP patients who failed NSAID treatment was 14,485 (48.50) (EF 729,944). Among them, one third failed only one NSAID treatment (33.1\%), one third (35.9\%) failed two treatments, $19.6 \%$ failed three treatments and $11.5 \%$ failed four treatments (Table 3 ). The number of OAP patients who failed opioid therapy was $14,250(47.71 \%)$ (EF 727,388$)$, of which 9117 (58.1\%\%) failed weak opioid treatment (EF 461,912), 2919 (20.48\%) strong opioid treatment (EF 147,375) and 2214 (15.54\%) both therapies (EF 118,101) (Table 4).

There were 3234 OAP patients intolerant to NSAIDs (10.83\%) (EF 168,559), 1988 to opioids (18.44\%) (EF 102,266) and 286 to both NSAIDs and opioids (0.96\%) (EF 14,882). Most patients intolerant to NSAIDs were treated with acetaminophen $(44.3 \%)$ and continued treatment with this type of therapy in successive therapies, either stand alone or in combination $(39.1 \%$ in second line and $65.7 \%$ in third line); $16.7 \%$ of patients intolerant to NSAIDs received tramadol/acetaminophen after showing intolerance and remained on that treatment in the second $(35.1 \%)$ and third (62.6\%) treatment lines. Patients intolerant to opioids were usually treated with acetaminophen (59\%) and continued receiving it in successive lines $(42.1 \%$ in second and $70.1 \%$ in third line); $16.3 \%$ of patients intolerant to opioids were prescribed metamizole after showing intolerance, and they received acetaminophen or metamizole or both in successive treatment lines.

The total number of OAP patients with one or more conditions associated with being inadequately treated (contraindication, failed therapy or intolerance) was 16,748 patients (56.08\%) (EF 838,620), taking into account the overlaps of patients between the considered 
IQVIA longitudinal patient data

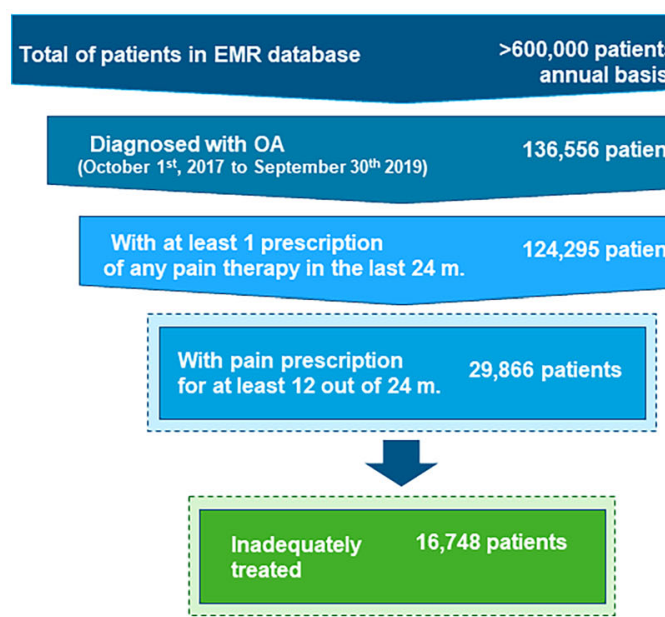

INE and extrapolation from IQVIA longitudinal patient data

\section{trats}

Spanish population over 15 y.o. NE (National Statistics Institute) 2018

$39,540,005$ subjects

\begin{tabular}{|c|c|}
\hline Patients with $O A$ in Spain & 6.507.046 patients \\
\hline $\begin{array}{l}\text { OA patients treated for } \\
\text { pain in Spain }\end{array}$ & 5.937.756 patients \\
\hline
\end{tabular}

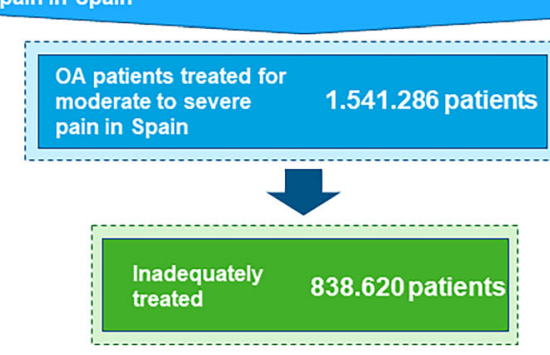

Fig. 1 Patients from the EMR database included in the analysis along with the corresponding figures extrapolated to the Spanish population

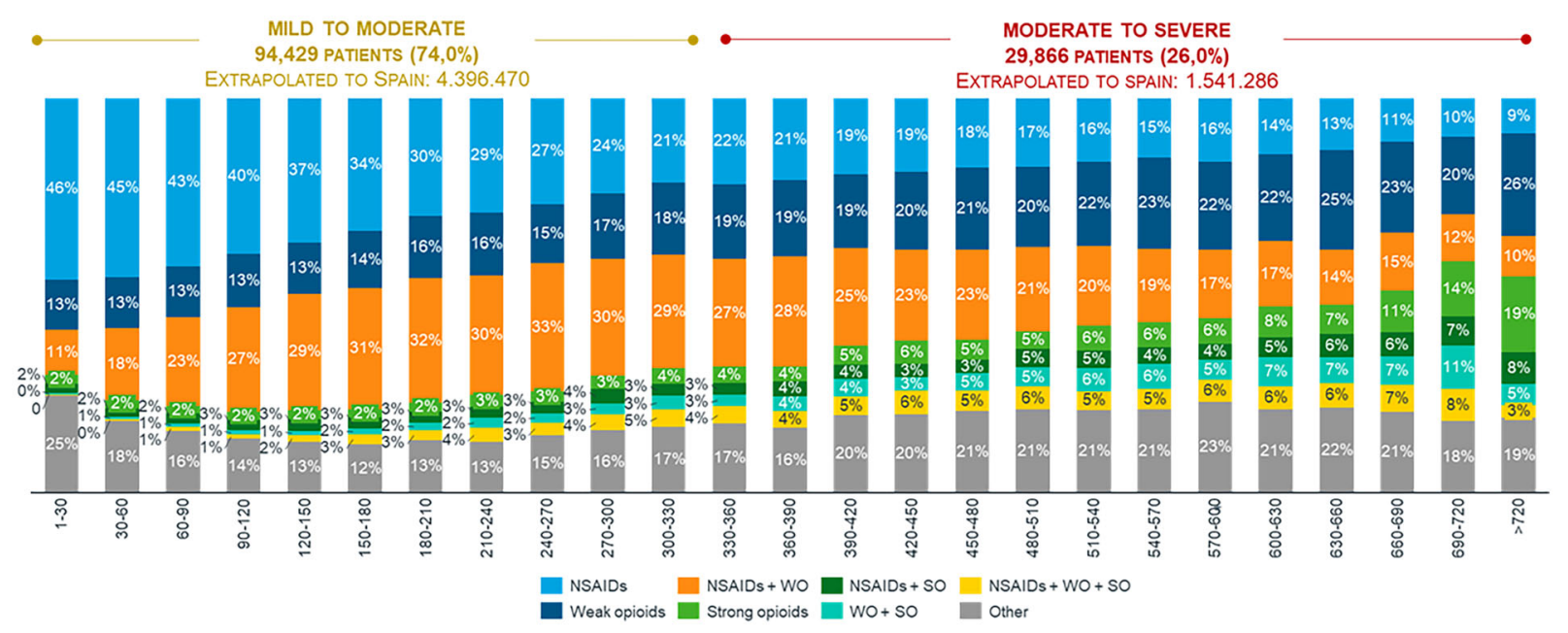

Fig. 2 Relative frequencies of different treatments received by patients with OA, depending on the length of time under treatment during the last 24 months. NSAIDs non-steroidal anti-inflammatory drugs; $W O$ weak opioids, $S O$ strong opioids

groups. Among OAP patients who failed NSAID therapy, half also failed opioid therapy (53.86\%): $7.86 \%$ had opioid intolerance and $5.50 \%$, opioid contraindication. Among OAP patients who failed opioid therapy, half also failed NSAID therapy (54.75\%), $12 \%$ had NSAID intolerance and $8.79 \%$ NSAID contraindication.

In most OAP patients (91\%), pain treatment was initiated by a general practitioner (GP) alone, in $6 \%$ by a specialist and in $3 \%$ by both. In the first referral, treatment was prescribed in $43 \%$ of the cases by specialists $(10 \%$ traumatologists, $5 \%$ pain management specialists, $4 \%$ rheumatologists and $2 \%$ physiatrists), in the other $43 \%$ by a combination of GPs and specialists and in $14 \%$ by GPs alone. Considering overall successive therapy lines, after the first prescription, pain drugs were prescribed by a GP in $61 \%$ of the cases, by a specialist in $20 \%$ and by both in $18 \%$.

At some point, $33 \%$ of OAP patients visited at least one of the four key specialists (traumatologist, rheumatologist, physiatrist and pain management specialist), whereas this 


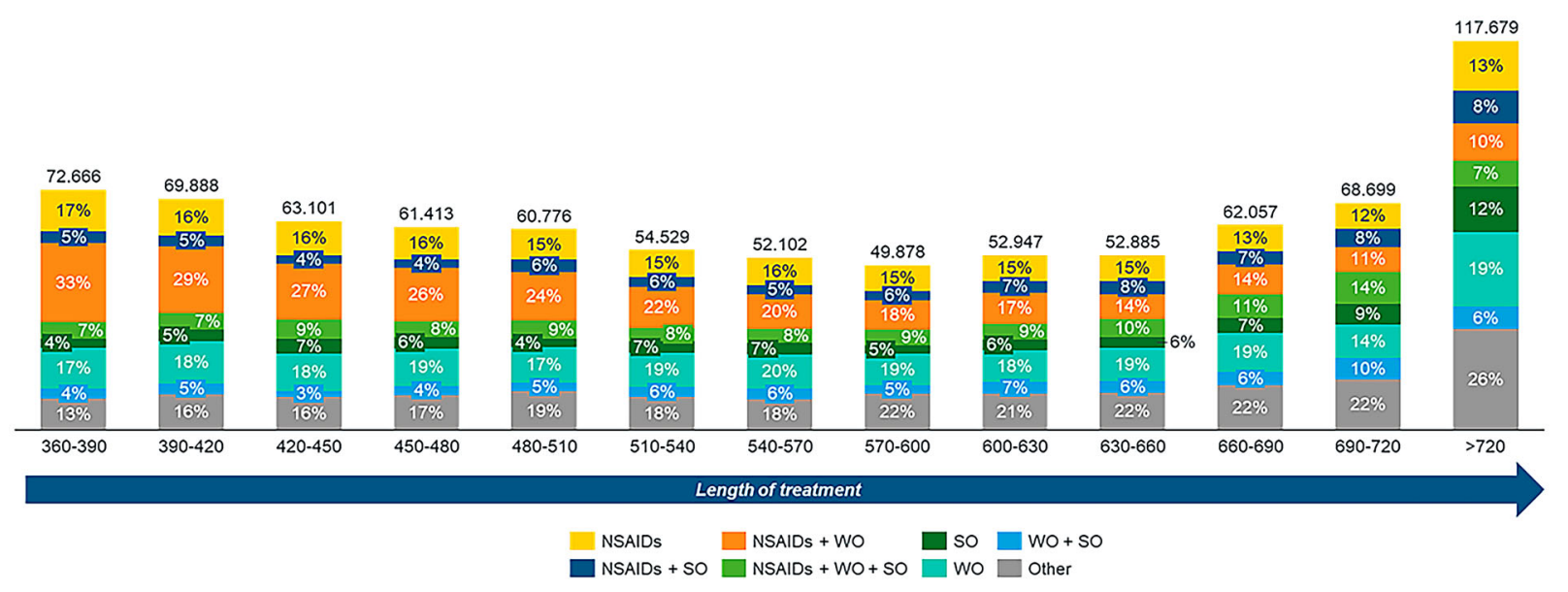

Fig. 3 Treatments received by patients with $\mathrm{OA}$ and moderate-to-severe pain at inclusion date depending on the length of time under treatment during the last

percentage was higher if patients had failed opioid treatment $(41 \%)$ or failed therapy with NSAIDs plus opioids (48\%), and even higher (59\%) if patients had failed strong opioid therapy. Looking to global referrals to specialists of OAP patients related to pain treatment, $15 \%$ of patients were referred at least once to traumatologists, $8 \%$ to physiatrists, $6 \%$ to rheumatologists and 3\% to pain management specialists. (In Figs. 1S-3S a detailed description of these referrals is shown.)

\section{DISCUSSION}

According to the presented analysis of a longitudinal patient-level database of Spanish patients, $22 \%$ of OA patients received treatment for pain for at least 12 out of 24 months, so they can be considered patients with moderate-tosevere pain (OAP). OAP patients had a high mean age ( 75 years) and almost three quarters were female. These figures are in agreement with previous studies that have shown a higher prevalence of $\mathrm{OA}$ in elderly patients and women [34-38].

More than a half of the OAP patients were treated with a NSAID, weak opioid or combination of both, but, as was shown, weak opioids were more frequently used in patients with mild pain and strong opioids in patients with
24 months and extrapolated figure of the number of patients in each group. Treatment length is expressed in days

moderate or severe pain. These treatments are included in different clinical guidelines from Spain [13-16] or other geographical regions [17-20], although long-term use of opioids is only recommended in select patients, as a thirdline therapy, with uncertainty about their longterm effectiveness and safety. A study carried out in five European countries has previously shown the high use of these pain treatments [28] as was also shown in studies carried out in Japan and Korea [36, 38, 39]. One study carried out in Japan [36] on a medical claims database between 2013 and 2019 showed that although NSAIDs were mostly used in hip (34.1-41.4\%) and knee OA (58.3-63.3\%), the use of acetaminophens and weak opioids increased from 2013 to 2019. Another study done in Japan [38] found that weak opioids were prescribed to $10.7 \%$ of OA patients and that acetaminophen prescriptions increased from 2013 to 2017. A study conducted in Japan and Korea [39] showed that the use of NSAIDs in OA patients was higher in Japan (74.7\%) than in Korea (59.0\%), where acetaminophen and symptomatic slow-acting drugs for osteoarthritis (SYSADOA) were more frequently used. In a study carried out by the "Good Life with OA" initiative in Denmark (GLA:D), the percentage of patients receiving acetaminophen, NSAIDs or opioids during the last 3 months was $56 \%$ in knee OA and 59\% in hip OA at study baseline 
Table 2 OA patients with moderate-to-severe pain who showed any contraindication to NSAIDs or opioids

\begin{tabular}{lll}
\hline NSAID contraindication & $\begin{array}{l}\text { OAP patients in the database } \\
n(\%)\end{array}$ & $\begin{array}{l}\text { OAP extrapolated } \\
n\end{array}$ \\
\hline Allergy to any NSAID & $55(2.01 \%)$ & 2678 \\
Severe heart failure & $723(26.38 \%)$ & 37,313 \\
Renal failure & $309(11.27 \%)$ & 14,770 \\
Severe hepatic failure & $90(3.28 \%)$ & 5308 \\
Active hemorrhage & $1166(42.54 \%)$ & 56,603 \\
History of gastrointestinal ulceration & $521(19.01 \%)$ & 24,640 \\
\hline Opioid contraindication & OAP patients in the database & OAP extrapolated to GP \\
\hline Elevated carbon dioxide levels in the blood & $2(0.12 \%)$ & 106 \\
Delayed gastric emptying & $11(0.66 \%)$ & 536 \\
Severe respiratory depression & $3(0.18 \%)$ & 93 \\
Cor pulmonale & $28(1.68 \%)$ & 1486 \\
Moderate-to-severe hepatic impairment & $1011(60.68 \%)$ & 49,457 \\
Chronic constipation & $634(38.06 \%)$ & 32,867 \\
\hline Number of patients $(n)$ in each group without considering the overlap with other groups. Percentages are estimated over the \\
total number of OAP patients with contraindication taking into account the overlap (2741 patients with NSAID con- \\
traindication and 1666 patients with opioid contraindication). Sum of percentages is $>100 \%$
\end{tabular}

[26]. In a similar study carried out in Sweden ("Better Management of Patients with OA"), this percentage of patients taking OA medication at baseline, before the intervention that was studied, was as high as $75 \%$ [23]. The number of patients who needed to use pain killers in these two latter studies was reduced after the patients were included in those programs. In the present study, frequency of use of NSAIDs and/or weak opioid treatments decreased as the time on treatment increased, in favor of strong opioids and their combinations with other drugs. The therapeutic alternatives are few, given the low efficacy of acetaminophen and the limitation of chronic NSAIDs.

The total number of OAP patients with one or more conditions associated with inadequate pain treatment (NSAID or opioid contraindication, failed NSAID or opioid therapy or intolerance to NSAIDs or opioids) in the present study was 16,748 patients $(56.08 \%)$. Extrapolating this figure to the Spanish general population, the figure is as high as 838,620 OAP patients who could be inadequately treated in Spain. A previous study comparing the use in clinical practice of pain medications in OA patients with recommended guidelines in the US [40] found that switching, augmentation or discontinuation therapy was frequently observed in real life and that this might suggest that patients did not achieve optimal pain relief or they experienced potentially intolerable therapy-related side effects.

Fifty percent of OAP patients have unmet needs due to the lack of efficacy or safety of NSAID or opioid therapy.

Almost a fifth of OAP patients showed intolerance to NSAIDs and/or opioids and, to a lesser degree, had contraindications to taking one of these therapeutic groups. The high frequency of adverse events in OA patients taking NSAIDs as continuous treatment has led to the recommendation of taking them for the shortest duration and the lowest possible dose [16]. 
Table 3 OA patients with moderate-to-severe pain who failed NSAID therapy

\begin{tabular}{|c|c|c|}
\hline & $\begin{array}{l}\text { OAP patients in } \\
\text { the database }\end{array}$ & $\begin{array}{l}\text { OAP } \\
\text { extrapolated } \\
\text { to GP }\end{array}$ \\
\hline \multicolumn{3}{|c|}{ Patients that failed 1 treatment } \\
\hline 1 NSAID & $4799(33.1 \%)$ & $\begin{array}{l}244,806 \\
\quad(33.5 \%)\end{array}$ \\
\hline \multicolumn{3}{|c|}{ Patients that failed 2 treatments } \\
\hline 1 NSAIDs +1 SO & $807(5.6 \%)$ & $41,471(5.7 \%)$ \\
\hline $\begin{array}{l}1 \text { NSAID + } 1 \\
\text { WO }\end{array}$ & $2878(19.9 \%)$ & $\begin{array}{l}146,102 \\
(20.0 \%)\end{array}$ \\
\hline 2 NSAIDs & $1510(10.4 \%)$ & $74,797(10.2 \%)$ \\
\hline \multicolumn{3}{|c|}{ Patients that failed 3 treatments } \\
\hline $\begin{array}{l}2 \text { NSAIDs + } 1 \\
\text { WO }\end{array}$ & $1128(7.8 \%)$ & $56,065(7.7 \%)$ \\
\hline $\begin{array}{l}1 \mathrm{NSAID}+1 \\
\mathrm{WO}+1 \mathrm{SO}\end{array}$ & $591(4.1 \%)$ & $30,244(4.1 \%)$ \\
\hline $\begin{array}{l}1 \text { NSAID + } 2 \\
\text { WO }\end{array}$ & $342(2.4 \%)$ & $17,157(2.4 \%)$ \\
\hline 2 NSAIDs $+1 \mathrm{SO}$ & $322(2.2 \%)$ & $16,127(2.2 \%)$ \\
\hline 3 NSAIDs & $326(2.3 \%)$ & $15,855(2.2 \%)$ \\
\hline $1 \mathrm{NSAID}+2 \mathrm{SO}$ & $120(0.8 \%)$ & $6155(0.8 \%)$ \\
\hline \multicolumn{3}{|c|}{ Patients that failed 4 treatments } \\
\hline $\begin{array}{l}4 \text { NSAID and } \\
\text { opioid } \\
\text { treatments }\end{array}$ & $1662(11.5 \%)$ & $79262(10.9 \%)$ \\
\hline
\end{tabular}

$S O$ strong opioid, $W O$ weak opioid

Among OAP patients who failed NSAID therapy, half also failed opioid therapy $(53.86 \%), 7.86 \%$ had opioid intolerance and $5.50 \%$ opioid contraindication. Among OAP patients who failed opioid therapy, half also failed NSAID therapy (54.75\%), 12\% had NSAID intolerance and $8.79 \%$ NSAID contraindication. These data show that options to treat these OAP patients are scarce, and there is a need for new treatments that can adequately relieve the
Table 4 OA patients with moderate-to-severe pain who failed opioid therapy

\begin{tabular}{lll}
\hline $\begin{array}{l}\text { OAP patients in } \\
\text { the database }\end{array}$ & $\begin{array}{l}\text { OAP } \\
\text { extrapolated } \\
\text { to GP }\end{array}$ \\
\hline
\end{tabular}

Patients that failed 1 treatment

$\begin{array}{lll}1 \text { WO } & 3757(26.4 \%) & 197,169(27 \%) \\ 1 \text { SO } & 1294(9.1 \%) & 68,570(9.4 \%)\end{array}$

Patients that failed 2 treatments

\begin{tabular}{|c|c|c|}
\hline $\begin{array}{l}1 \text { NSAID + } 1 \\
\text { WO }\end{array}$ & $2878(20.2 \%)$ & $\begin{array}{l}146,102 \\
(20.0 \%)\end{array}$ \\
\hline 1 NSAID + 1 SO & $807(5.7 \%)$ & $41,471(5.7 \%)$ \\
\hline $1 \mathrm{WO}+1 \mathrm{SO}$ & $709(5.0 \%)$ & $27,759(5.1 \%)$ \\
\hline $2 \mathrm{SO}$ & $169(1.2 \%)$ & $8,974(1.2 \%)$ \\
\hline $2 \mathrm{WO}$ & $313(2.2 \%)$ & $16,108(2.2 \%)$ \\
\hline \multicolumn{3}{|c|}{ Patients that failed 3 treatments } \\
\hline $\begin{array}{l}2 \text { NSAIDs + } 1 \\
\text { WO }\end{array}$ & $1128(7.9 \%)$ & $56,065(7.7 \%)$ \\
\hline $\begin{array}{l}1 \text { NSAID + } 1 \\
\text { WO + } 1 \text { SO }\end{array}$ & $591(4.1 \%)$ & $30,244(4.1 \%)$ \\
\hline $\begin{array}{l}1 \text { NSAID + } 2 \\
\text { WO }\end{array}$ & $342(2.4 \%)$ & $17,157(2.3 \%)$ \\
\hline 2 NSAIDs + 1 SO & $322(2.3 \%)$ & $16,127(2.2 \%)$ \\
\hline $1 \mathrm{NSAID}+2 \mathrm{SO}$ & $120(0.8 \%)$ & $6,155(0.8 \%)$ \\
\hline $2 \mathrm{SO}+1 \mathrm{WO}$ & $104(0.7 \%)$ & $5,428(0.7 \%)$ \\
\hline $1 \mathrm{SO}+2 \mathrm{WO}$ & $67(0.5 \%)$ & $3,393(0.5 \%)$ \\
\hline $3 \mathrm{SO}$ & $19(0.1 \%)$ & $1,027(0.1 \%)$ \\
\hline
\end{tabular}

Patients that failed 4 treatments

\begin{tabular}{l}
$\begin{array}{l}4 \text { NSAIDs and } \\
\text { opioid treatments }\end{array}$ \\
\hline
\end{tabular}

$S O$ strong opioid, $W O$ weak opioid

moderate-to-severe pain that these patients experience.

OA patients with moderate-to-severe pain are treated mostly by GPs at the initiation of treatment but also later as the patient requires changes in pain medication. Although it can be 
considered normal that GP doctors are the first physicians involved in the pain management of these patients, mainly taking into account the existing rules of patient management in Spain, it seems clear that there is room for improvement regarding the involvement of specialists in treating these patients with moderate-tosevere pain because only $6 \%$ of OAP patients were treated by them at the start. For these patients, the access to specialized health professionals has been associated with effective management and improved outcomes [37]. The high participation of GPs in the pain management found in the present study is in agreement to what it was shown in a study carried out by the Spanish Pain Society in which $83 \%$ of patients with pain were treated in primary care [11]. In the first referral, specialists accounted for almost half of the treatment prescriptions, but again it seems that the management of OAP patients could be improved, as only half of these specialists belonged to one of the specialties with the appropriate training for adequate pain management in $\mathrm{OA}$ patients (traumatologist, pain management specialist, rheumatologist and physiatrist) with the traumatologists the main specialists involved with only $10 \%$ of pain prescriptions at first referral. It is noteworthy that only $2 \%$ of the patients who were referred for the first time were referred to a pain unit. This may be related to the fact that GPs in Spain cannot directly refer patients to the pain management specialist, so patient management could benefit of having this direct referral from primary care. Only 33\% of OA patients with moderate-to-severe pain visited at least one of the four key specialists. This percentage was higher if patients had failed opioid treatment, NSAID plus opioid and strong opioid therapy. OA patients referred to rheumatologists in a study conducted in Canada had been previously treated by family physicians with NSAID $(38.2 \%)$, oral steroid $(3.0 \%)$ or steroid joint injection (3.8\%) [37], so it seems that Canadian GPs do not necessarily have to finish all therapeutic lines to refer patients to specialists. The under-referral of OA patients can lead to delays in appropriate care management and treatment [37]. The lack of participation of specialists in pain management was already shown by previous studies in Spain [11], although in other countries, like Canada, the involvement of rheumatologists is clearly more frequent: according to a published study [37], $32 \%$ of the referrals received by rheumatologists in the Canadian region of Ontario were related to OA. The holistic management of patients with $\mathrm{OA}$, through the implementation of medical programs specifically designed for these patients, could significantly improve the outcomes currently achieved in Spain. These initiatives, like the "Osteoarthritis Chronic Care Program (OACCP)" in Australia [21, 22], "Better Management of Patients with Osteoarthritis (BOA)" program in Sweden [23, 24], "Enabling Self-Management and Coping with Arthritic Pain using Exercise (ESCAPE)" program in the UK [25] and "Good Life with Osteoarthritis in Denmark (CLA:D)" program in Denmark [26], are best practices for delivering the core treatment strategy recommended by the OA guidelines worldwide, which involve the patient in their self-management and give physiotherapists, occupational therapists and nutritionists an important role in patient care.

One clear limitation of the present study is that it was necessary to make some assumptions about the different reasons for patients being inadequately treated due to the limitations of the EMR database, as all databases have. Another weakness of the EMR database that was used in this analysis is that it is not possible to differentiate between locations of OA (hip, knee, hands...), the number of affected joints and the severity of OA measured in terms of progression of joint disease. It is also important to note that it was not possible to consider interventional procedures used to mitigate the pain, such as infiltrations, radiofrequency rhizotomy, electrical stimulation, etc. The number of OA patients included in the database used in this study and the high representativeness with respect to the general population from Spain and the variety of specialists included are advantages of the analysis performed and presented in this article. 


\section{CONCLUSIONS}

The present work showed that more than half of the patients with OA in Spain have unsatisfactory pain control. Pain drugs are mainly prescribed by GPs, and specialists (traumatologists, rheumatologists, physiatrists and pain management specialists) are not very involved in the management of OAP patients.

\section{ACKNOWLEDGEMENTS}

Funding. Sponsorship for this study and Rapid Service Fee were funded by Pfizer S.L.U.

Authorship. All named authors meet the International Committee of Medical Journal Editors (ICMJE) criteria for authorship for this article, take responsibility for the integrity of the work as a whole, and have given their approval for this version to be published.

Authors' Contributions. Francisco CastroDomínguez, Francisco Vargas-Negrín and Concepción Pérez have substantially contributed to the interpretation of data for the work, have revised it critically for important intellectual content, have approved the final version to be published and are accountable for all aspects of the work; Héctor Gutiérrez-Prieto and Pablo Rebollo have substantially contributed to the data acquisition, analysis and interpretation of data for the work, have revised it critically, have approved the final version to be published and are accountable for all aspects of the work.

Disclosures. Francisco Castro-Domínguez, Francisco Vargas Negrin and Concepción Pérez declare that they have no conflict of interest. Héctor Gutiérrez-Prieto and Pablo Rebollo were employees of IQVIA and received an honorarium from Pfizer in connection with the development of this manuscript.

Compliance with Ethics Guidelines. The protocol of this study was approved by the Research Ethical Committee of Hospital Clinic of Barcelona on 26 November 2020 (Reg.HCB/
2020/1309). This study was performed in accordance with the Helsinki Declaration of 1964 and its later amendments. Patient consent was not obtained as Spanish legislation excludes existing data that are aggregated for analysis and personal data are stripped of identifying details as specified in Organic Law 3/2018.

Data Availability. The datasets generated and analyzed during the current study are databases owned by IQVIA.

Open Access. This article is licensed under a Creative Commons Attribution-NonCommercial 4.0 International License, which permits any non-commercial use, sharing, adaptation, distribution and reproduction in any medium or format, as long as you give appropriate credit to the original author(s) and the source, provide a link to the Creative Commons licence, and indicate if changes were made. The images or other third party material in this article are included in the article's Creative Commons licence, unless indicated otherwise in a credit line to the material. If material is not included in the article's Creative Commons licence and your intended use is not permitted by statutory regulation or exceeds the permitted use, you will need to obtain permission directly from the copyright holder. To view a copy of this licence, visit http://creativecommons.org/licenses/bync/4.0/.

\section{REFERENCES}

1. Casals M, Samper D. Epidemiology, prevalence and quality of life of non-malignant chronic pain. ITACA study. Rev Soc Esp Dolor. 2004;11:260-9.

2. Morgado I, Pérez AC, Moguel M, Pérez-Bustamante FJ, Torres LM. Guide for the clinical management of osteoarthritis of the hip and the knee. Rev Soc Esp Dolor. 2005;12:289-302.

3. Monfort J. Artrosis, Fisiopatología, diagnóstico y tratamiento. Sociedad Española de Reumatología, editor: Ed. Médica Panamericana; 2010.

4. Blanco FJ, Silva-Díaz M, Quevedo Vila V, et al. Prevalence of symptomatic osteoarthritis in Spain: 
EPISER2016 study. Reumatologia clinica. 2020. https://pubmed.ncbi.nlm.nih.gov/32360025/.

5. INE. Encuesta Nacional de Salud. Accessed: Oct 20, 2020. https://www.ine.es/dynt3/inebase/es/index. htm?type=pcaxis\&path=/t15/p419/a2017/p04/ \&file=pcaxis.

6. Carmona L, Ballina J, Gabriel R, Laffon A. The burden of musculoskeletal diseases in the general population of Spain: results from a national survey. Ann Rheum Dis. 2001;60(11):1040-5.

7. Val Jiménez CL, López-Torres Hidalgo J, García Atienza EM, et al. Functional status, self-rated health and level of physical activity of patients with osteoarthritis. Aten Primaria. 2017;49(4):224-32.

8. Puig-Junoy J, Ruiz ZA. Socio-economic costs of osteoarthritis: a systematic review of cost-of-illness studies. Semin Arthritis Rheum. 2015;44(5):531-41.

9. Langleypaul C, Jesús Tornero M, César Margarit F, et al. The association of pain with labor force participation, absenteeism, and presenteeism in Spain. J Med Econ. 2011;14(6):835-45.

10. Losina E, Walensky RP, Reichmann WM, et al. Impact of obesity and knee osteoarthritis on morbidity and mortality in older Americans. Ann Intern Med. 2011;154(4):217-26.

11. Torralba A, Miquel A, Darba J. Current status of chronic pain in Spain: "Pain Proposal" initiative. Rev Soc Esp Dolor. 2014;21(1):16-22.

12. Phillips CJ, Harper C. The economics associated with persistent pain. Curr Opin Support Palliat Care. 2011;5(2):127-30.

13. Giménez Basallote S, Caballero Vega J, Martín Jiménez J, Sánchez Fierro J, García García A. Guía práctica para el tratamiento en atención primaria de la artrosis en pacientes con comorbilidad 2016 November 10th 2020:[62 p.]. https://www.semg.es/ images/documentos/2017/documentos/guia_tto_ artrosis.pdf.

14. Toquero de la Torre F, Rodríguez Sendín JJ. Guía de buena práctica clínica en artrosis. Atención primaria de calidad [Internet]. 2008 November 10th 2020:[88 p.]. https://www.cgcom.es/sites/default/ files/guia_artrosis_edicion2.pdf.

15. Gracia San Román FJ, Calcerrada Díaz-Santos N. Guía de práctica clínica del manejo del paciente con artrosis de rodilla en Atención Primaria2006 November 10th 2020:[77 p.]. https://www. comunidad.madrid/sites/default/files/aud/sanidad/ guia_del_manejo_del_paciente_con_artrosis_de_ rodilla_en_atencion_primaria.pdf.
16. Lanas A, Benito P, Alonso J, et al. Safe prescription recommendations for non steroidal anti-inflammatory drugs: consensus document ellaborated by nominated experts of three scientific associations (SER-SEC-AEG). Reumatologia clinica. 2014;10(2): 68-84.

17. Kolasinski SL, Neogi T, Hochberg MC, et al. 2019 American College of Rheumatology/arthritis foundation guideline for the management of osteoarthritis of the hand, hip, and knee. Arthritis Care Res. 2020;72(2):149-62.

18. Geenen R, Overman CL, Christensen R, et al. EULAR recommendations for the health professional's approach to pain management in inflammatory arthritis and osteoarthritis. Ann Rheum Dis. 2018;77(6):797-807.

19. National Collaborating Centre for Chronic Conditions. Osteoarthritis: National Clinical Guideline for Care and Management in Adults2008 November 10th 2020. http://europepmc.org/abstract/MED/ 21290638.

20. Bannuru RR, Osani MC, Vaysbrot EE, et al. OARSI guidelines for the non-surgical management of knee, hip, and polyarticular osteoarthritis. Osteoarthritis Cartilage. 2019;27(11):1578-89.

21. ACI. Osteoarthritis chronic care program model of care. Agency for clinical innovation; Accessed: Nov 10th. https:/aci.health.nsw.gov.au/resources/ musculoskeletal/osteoarthritis_chronic_care_ program/osteoarthritis-chronic-care-program.

22. Eyles JP, Bowden JL, Redman S, et al. Barriers and enablers to the implementation of the Australian Osteoarthritis Chronic Care Program (OACCP). Osteoarthritis Cartilage. 2020;28:662.

23. Jönsson T, Eek F, Dell'Isola A, Dahlberg LE, Ekvall Hansson E. The Better management of patients with Osteoarthritis Program: outcomes after evidence-based education and exercise delivered nationwide in Sweden. PLoS ONE. 2019;14(9): e0222657.

24. Thorstensson CA, Garellick G, Rystedt H, Dahlberg LE. Better management of patients with osteoarthritis: development and nationwide implementation of an evidence-based supported osteoarthritis self-management programme. Musculoskeletal Care. 2015;13(2):67-75.

25. Hurley MV, Walsh NE, Mitchell HL, et al. Clinical effectiveness of a rehabilitation program integrating exercise, self-management, and active coping strategies for chronic knee pain: a cluster randomized trial. Arthritis Rheum. 2007;57(7):1211-9. 
26. Skou ST, Roos EM. Good Life with osteoarthritis in Denmark (GLA:D $\left.{ }^{\mathrm{TM}}\right)$ : evidence-based education and supervised neuromuscular exercise delivered by certified physiotherapists nationwide. BMC Musculoskelet Disord. 2017;18(1):72.

27. Filardo G, Kon E, Longo UG, et al. Non-surgical treatments for the management of early osteoarthritis. Knee Surg Sports Traumatol Arthrosc. 2016;24(6):1775-85.

28. Kingsbury SR, Gross HJ, Isherwood G, Conaghan PG. Osteoarthritis in Europe: impact on health status, work productivity and use of pharmacotherapies in five European countries. Rheumatology (Oxford). 2014;53(5):937-47.

29. Langley PC, Ruiz-Iban MA, Molina JT, De Andres J, Castellón JR. The prevalence, correlates and treatment of pain in Spain. J Med Econ. 2011;14(3): 367-80.

30. AEMPS. Utilización de medicamentos opioides en España. Accessed: Oct 20, 2020. https://www. aemps.gob.es/medicamentos-de-uso-humano/ observatorio-de-uso-de-medicamentos/utilizacionde-medicamentos-opioides-en-espana-durante-elperiodo-2010-2018/.

31. Hurtado I, García-Sempere A, Peiró S, Sanfélix-Gimeno G. Increasing trends in opioid use from 2010 to 2018 in the region of Valencia, Spain: a realworld, population-based study. Front Pharmacol. 2020;11:612556.

32. Orozco-Arango JA. Interventional therapies for pain management in symptomatic knee osteoarthrosis. Rev Soc Esp Dolor. 2017;24(6):324-32.

33. Organic Law 3/2018, of December 5, on Data Protection and Guarantee of Digital Rights. 294.
Official State Gazette (Boletin Oficial del Estado) 2018. p. $119788-857$.

34. Srikanth VK, Fryer JL, Zhai G, et al. A meta-analysis of sex differences prevalence, incidence and severity of osteoarthritis. Osteoarthritis Cartilage. 2005;13(9):769-81.

35. Vina ER, Kwoh CK. Epidemiology of osteoarthritis: literature update. Curr Opin Rheumatol. 2018;30(2):160-7.

36. Ebata-Kogure N, Murakami A, Nozawa K, et al. Treatment and healthcare cost among patients with hip or knee osteoarthritis: a cross-sectional study using a real-world claims database in Japan between 2013 and 2019. Clin Drug Investig. 2020;40(11): 1071-84.

37. Widdifield J, Tu K, Carter TJ, et al. Patterns of care among patients referred to rheumatologists in Ontario. Can Arthritis Care Res. 2017;69(1):104-14.

38. Akazawa M, Mimura W, Togo K, et al. Patterns of drug treatment in patients with osteoarthritis and chronic low back pain in Japan: a retrospective database study. J Pain Res. 2019;12:1631-48.

39. Sakai R, Cho SK, Jang EJ, Harigai M, Sung YK. International descriptive study for comparison of treatment patterns in patients with knee osteoarthritis between Korea and Japan using claims data. Int J Rheum Dis. 2019;22(11):2052-8.

40. Gore M, Sadosky A, Leslie D, Tai KS, Seleznick M. Patterns of therapy switching, augmentation, and discontinuation after initiation of treatment with select medications in patients with osteoarthritis. Clin Ther. 2011;33(12):1914-31. 